\title{
Seasonal development of a deep pelagic bioluminescent layer in the temperate NE Atlantic Ocean
}

\author{
E. J. V. Gillibrand ${ }^{1,3, *}$, A. J. Jamieson ${ }^{1}$, P. M. Bagley ${ }^{1}$, A. F. Zuur ${ }^{2}$, I. G. Priede ${ }^{1, * *}$ \\ ${ }^{1}$ Oceanlab, University of Aberdeen, Main Street, Newburgh, Aberdeen AB41 6AA, UK \\ ${ }^{2}$ Highland Statistics Ltd, 6 Laverock Road, Newburgh, Aberdeen AB41 6FN, UK \\ ${ }^{3}$ Present address: Robert Gordon University, Schoolhill, Aberdeen AB10 1FR, UK
}

\begin{abstract}
Vertical distribution of bioluminescent organisms throughout the water column in the Porcupine Seabight and Porcupine Abyssal plain area of the NE Atlantic Ocean was measured using a free-falling autonomous vehicle equipped with a high-sensitivity video system viewing stimulated flashes of light from impacts on a mesh screen. Data were recorded from $500 \mathrm{~m}$ depth down to the sea floor at depths from 740 to $4808 \mathrm{~m}$ during spring and autumn of 2001 and 2002. Bioluminescent organisms decreased in abundance from a maximum of $80 \mathrm{~m}^{-3}$ at $600 \mathrm{~m}$ depth to a mean of 0.5 to $1.2 \mathrm{~m}^{-3}$ at depths greater than $3000 \mathrm{~m}$. During autumn, a seasonally enhanced peak of abundance (mean $27.19 \mathrm{~m}^{-3}$, compared with $7.52 \mathrm{~m}^{-3}$ in spring) centred at $1420 \mathrm{~m}$ within the depth range of occurrence of Mediterranean intermediate water. It is hypothesised that this bioluminescent layer reflects seasonal increase in deep pelagic biomass fed by downward transport of organic matter following the spring peak of primary production in the surface layers. The bioluminescent layer is a large-scale regional phenomenon extending over 100s of kilometres.
\end{abstract}

KEY WORDS: Bioluminescence $\cdot$ Deep pelagic $\cdot$ NE Atlantic Ocean $\cdot$ Mediterranean intermediate water · Pelagic-benthic flux

\section{INTRODUCTION}

A defining feature of the deep-sea environment is the absence of solar light at depths greater than $1000 \mathrm{~m}$ and the widespread bioluminescent capacity and corresponding optical adaptations of fauna living there (Herring 1990). Despite this, there is little quantitative information on the distribution and abundance of bioluminescence organisms at these depths. Studies on bioluminescence are generally confined to surface observations (Miller et al. 2005) and depths less than $1000 \mathrm{~m}$ using submersibles and bathyphotometers lowered on cables from ships (Widder et al. 1999, Herren et al. 2005). In the NW Atlantic, Clarke \& Hubbard (1959) made measurements of bioluminescence at different depths down to the sea floor at $3750 \mathrm{~m}$ using a photomultiplier tube. In the Pacific Ocean, Bradner et al. (1987) measured continuous profiles down to $4300 \mathrm{~m}$ and Webster et al. (1991) incorporated a photo-multiplier tube into a free-fall system that descended to the sea floor at $4700 \mathrm{~m}$. All these studies confirmed the presence of bioluminescence at all depths with light occurring in flashes of 0.2 to $>1 \mathrm{~s}$ duration that decreased in frequency with increasing depth. Webster et al. (1991) detected 5 flashes $\mathrm{h}^{-1}$ above the sea floor of the Pacific Ocean. Interpretation of these results is problematic since the flashes can be stimulated by the motion of the sensor through the water, or motion of water past a static sensor. Bathyphotometers in which water is agitated by pumping through a photodetector chamber provide a means of measuring total stimulable luminescence in the water, but Clarke \& Kelly (1965) found their system inefficient at detecting larger luminescent animals found at depths greater than 400 to $900 \mathrm{~m}$. 
Closed volume bathyphotometers are generally used at depths of less than $1000 \mathrm{~m}$ (Herren et al. 2005) and provide an indirect measure of the abundance and spatial distribution of bioluminescent organisms.

A mesh screen mounted in front of a video camera traversed through the water provides a means of directly counting numbers of luminescent organisms and determining their 3-dimensional distribution. The screen mounted at the focal distance of the camera with its plane perpendicular to the direction of motion stimulates luminescence from organisms impacting on, or passing through the mesh. Originally used for horizontal transects from a manned submersible, this 'splat' screen technique provided the first insight into concentrations of luminescent organisms at thin layers in the water column off the Gulf of Maine (Widder et al. 1999, Widder \& Johnsen 2000). The concept has been further developed by Priede et al. (2006) to measure vertical profiles of distribution of bioluminescent organisms. With a downward-looking ISIT (intensified silicon intensified target) camera and a horizontal screen mounted on an unmanned free-fall lander vehicle, profiling is possible down to a maximum depth of $6000 \mathrm{~m}$. We have used this free-falling ISIT lander for a time series study in the temperate NE Atlantic Ocean west of Ireland. Preliminary results (Battle et al. 2002) indicated seasonal changes in abundance of luminescent organisms between 1000 and $2000 \mathrm{~m}$ depth. Using data from cruises in spring and autumn of 2 successive years, 2001 and 2002, and applying additive modelling methods, we now provide the first extensive information on seasonal change in abundance of bathypelagic luminescent organisms down to the abyssal sea floor.

\section{MATERIALS AND METHODS}

Field measurements. Vertical distribution of bioluminescent organisms was measured using a free-fall lander vehicle ballasted to descend at $35 \mathrm{~m} \mathrm{~min}^{-1}$ from the surface to the sea floor (Priede et al. 2006). An ISIT camera (OE1325: Kongsberg Simrad) looking vertically downwards was focussed on a $0.38 \times$ $0.5 \mathrm{~m}$ mesh screen with a $8 \times 16 \mathrm{~mm}$ pitch that filled the entire field of view at $0.5 \mathrm{~m}$ range. Light output from organisms, stimulated by impact on, or passage through, the mesh was recorded onto a $60 \mathrm{~min}$ miniature digital video recorder (Walkman GV-D300; Sony). An ultrasonic current meter (UCM-60; Sensortec) with an internal clock and pressure sensor provided precise measurement of depth. The camera and video recorder were controlled by a custom-built logging system which was programmed to start sampling at approximately $200 \mathrm{~m}$ depth to avoid potential damage to the camera tube from high ambient light levels near the surface. When the depth was greater than $2300 \mathrm{~m}$, corresponding to an expected descent time greater than the $60 \mathrm{~min}$ capacity of the system, an intermittent recording programme was used to distribute sampling throughout the water column. After the lander reached the sea floor, ballast was released by acoustic command from the ship and the system ascended by buoyancy to the surface for retrieval and downloading of data.

Nineteen vertical profiles with the ISIT lander were performed over a 2 yr period in the Porcupine Seabight and Abyssal Plain regions of the NE Atlantic Ocean during 4 research cruises of the RRS 'Discovery' in March and August 2001 and April and October 2002 (Table 1). Stations were distributed along an east-west transect at ca. $49^{\circ} \mathrm{N}$ from 740 to $4808 \mathrm{~m}$ water depth, a distance of $380 \mathrm{~km}$ (Fig. 1). Occasional conductivity, temperature and depth profiles were taken using a standard CTD rosette (Sea-bird).

Table 1. List of intensified silicon intensifier target (ISIT) lander deployments (Deploy) showing times of descent and depths (bottom soundings). Deployments were treated as spring or autumn in the analysis

\begin{tabular}{|ccccccr|}
\hline $\begin{array}{l}\text { Cruise } \\
\text { Deploy } \\
\text { no. }\end{array}$ & $\begin{array}{c}\text { Station } \\
\text { no. }\end{array}$ & $\begin{array}{c}\text { Date } \\
(\mathrm{d} / \mathrm{mo} / \mathrm{yr})\end{array}$ & $\begin{array}{c}\text { Time } \\
(\mathrm{h})\end{array}$ & $\begin{array}{c}\text { Lat. } \\
(\mathrm{N})\end{array}$ & $\begin{array}{c}\text { Long. } \\
(\mathrm{W})\end{array}$ & $\begin{array}{c}\text { Depth } \\
(\mathrm{m})\end{array}$ \\
\hline $\begin{array}{l}\text { D252 (spring) } \\
1\end{array}$ & & & & & \\
2 & 13939 & $18 / 04 / 2001$ & $23: 03$ & $50^{\circ} 09.05^{\prime}$ & $14^{\circ} 28.75^{\prime}$ & 3939 \\
3 & 13943 & $19 / 04 / 2001$ & $22: 56$ & $50^{\circ} 05.46^{\prime}$ & $14^{\circ} 27.99^{\prime}$ & 3981 \\
4 & 13947 & $21 / 04 / 2001$ & $11: 14$ & $50^{\circ} 08.02^{\prime}$ & $14^{\circ} 29.95^{\prime}$ & 3977 \\
5 & $13961-1$ & $26 / 04 / 2001$ & $12: 26$ & $49^{\circ} 50.15^{\prime}$ & $11^{\circ} 29.86^{\prime}$ & 740 \\
D255 (autumn) & & & & & & \\
6 & 14135 & $17 / 08 / 2001$ & $16: 12$ & $49^{\circ} 16.03^{\prime}$ & $13^{\circ} 28.95^{\prime}$ & 4020 \\
7 & 14139 & $19 / 08 / 2001$ & $23: 04$ & $49^{\circ} 51.10^{\prime}$ & $13^{\circ} 02.21^{\prime}$ & 2487 \\
8 & $14144-1$ & $22 / 08 / 2001$ & $13: 21$ & $49^{\circ} 51.09^{\prime}$ & $13^{\circ} 02.82^{\prime}$ & 2494 \\
9 & 14148 & $23 / 08 / 2001$ & $20: 21$ & $49^{\circ} 30.13^{\prime}$ & $13^{\circ} 42.37^{\prime}$ & 4000 \\
10 & 14154 & $25 / 08 / 2001$ & $01: 20$ & $48^{\circ} 33.99^{\prime}$ & $15^{\circ} 00.11^{\prime}$ & 4784 \\
11 & 14157 & $27 / 08 / 2001$ & $13: 46$ & $50^{\circ} 00.03^{\prime}$ & $13^{\circ} 23.07^{\prime}$ & 280 \\
D260 (spring) & & & & & \\
12 & 14305 & $15 / 03 / 2002$ & $10: 55$ & $49^{\circ} 45.06^{\prime}$ & $13^{\circ} 56.68^{\prime}$ & 4018 \\
13 & 14310 & $16 / 03 / 2002$ & $15: 00$ & $49^{\circ} 51.40^{\prime}$ & $13^{\circ} 57.72^{\prime}$ & 3901 \\
14 & 14318 & $19 / 03 / 2002$ & $14: 20$ & $49^{\circ} 33.30^{\prime}$ & $14^{\circ} 11.00^{\prime}$ & 4271 \\
15 & 14320 & $20 / 03 / 2002$ & $13: 23$ & $49^{\circ} 48.42^{\prime}$ & $14^{\circ} 03.86^{\prime}$ & 3995 \\
D266 (autumn) & & & & & \\
16 & $15054-4$ & $03 / 10 / 2002$ & $11: 44$ & $49^{\circ} 01.93^{\prime}$ & $16^{\circ} 08.96^{\prime}$ & 4810 \\
17 & $15054-19$ & $08 / 10 / 2002$ & $14: 41$ & $48^{\circ} 46.63^{\prime}$ & $16^{\circ} 29.07^{\prime}$ & 4808 \\
18 & $15055-1$ & $12 / 10 / 2002$ & $21: 37$ & $49^{\circ} 27.88^{\prime}$ & $15^{\circ} 34.20^{\prime}$ & 4728 \\
19 & 15059 & $14 / 10 / 2002$ & $14: 30$ & $49^{\circ} 46.75^{\prime}$ & $13^{\circ} 37.65^{\prime}$ & 2927 \\
\hline
\end{tabular}




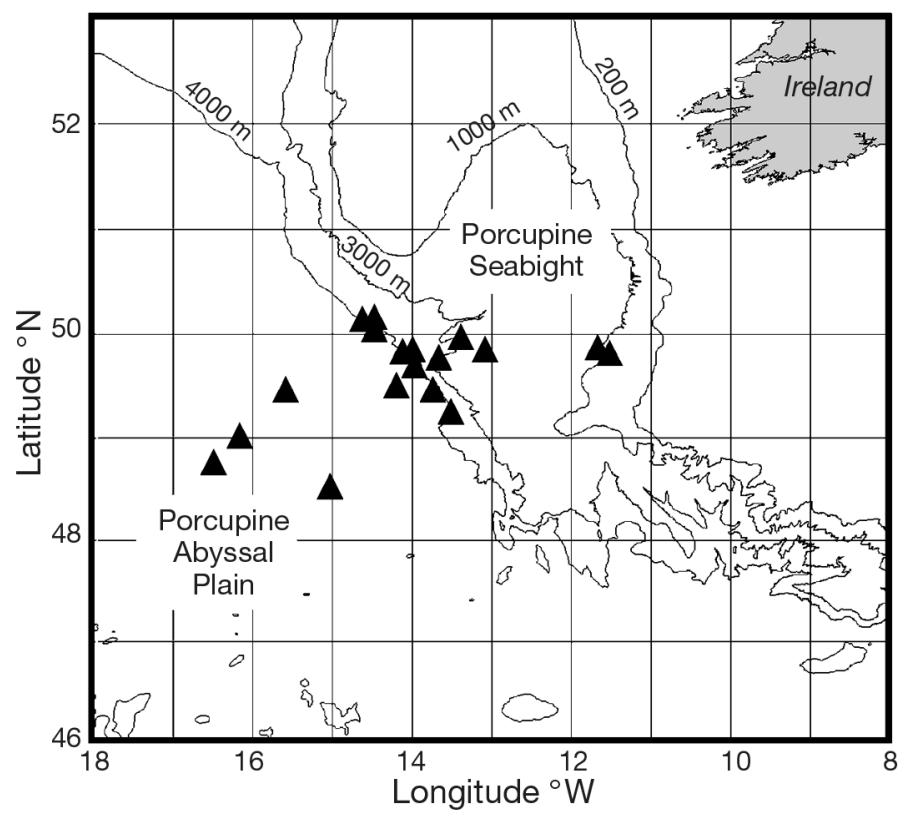

Fig. 1. Study area in the NE Atlantic Ocean showing deployment locations $(\boldsymbol{\Delta})$ of the free-fall ISIT profiler

Analysis. Each digital videotape was replayed and the number of bioluminescent events $\min ^{-1}$ counted. A transparent overlay on the video screen allowed marking off of sources as they were counted to avoid multiple counts of the same organism. Using the known mesh area and descent rate (giving volume of water through which the mesh screen moved $\min ^{-1}$ ), these data were converted to number of sources $\mathrm{m}^{-3}$ water at approximately $35 \mathrm{~m}$ depth intervals, depending on minor variations in descent rate of the system. This was chosen to correspond to a convenient volume increment of $6.13 \mathrm{~m}^{3}$ which would give a count of ca. 3 sources at typical sparse abyssal source densities and avoid problems of numerous zero values. Because of the sensitivity of the ISIT camera that could detect ambient light below $250 \mathrm{~m}$ depth, small bioluminescent events could not be reliably discriminated from background light near the surface. Thus, to reduce error, bioluminescent events recorded at depths shallower than $500 \mathrm{~m}$ were excluded from the analyses.

To relate the number of luminescent sources to sample depth, additive modelling (AM) was used. An AM is a generalised additive model with a Gaussian distribution and identity link function (Hastie \& Tibshirani 1990, Faraway 2006, Wood 2006, Zuur et al. 2007). AM was used because an initial linear regression model applied to the data showed residual patterns indicating non-linear relationships (Zuur et al. 2007). Cross-validation (Wood 2006) was used to estimate the optimal amount of smoothing. Because the data were measured in different deployments, we also used 'deployment' as a random effect.

\section{RESULTS}

The fundamental assumption in this study was that all bioluminescent organisms impinging on, or passing through, the mesh screen emitted some detectable light. This was recorded as an event corresponding to a single luminescent source in the water column. Active fauna such as squid or fish that might be able to avoid the mesh screen would not be detected. The most abundant (>75\%) sources were small planktonic organisms (e.g. copepods) that passed through the screen producing a single flash or trail of light $(<5 \mathrm{~mm}$ diameter) before exiting the field of view of the camera (Fig. 2a). Since the camera was $0.5 \mathrm{~m}$ from the mesh screen and descent rate was equivalent to $0.58 \mathrm{~m} \mathrm{~s}^{-1}$ the maximum dwell time of plankton (ignoring motility) within the field of view was $<860 \mathrm{~ms}$ and typically $<500 \mathrm{~ms}$. A second type of source was large planktonic or chain-forming organisms (>5 mm diameter) that generally disintegrated on screen (Fig. 2b). These constituted about $20 \%$ of observations. The third type (ca. $2 \%$ of sources) were gelatinous organisms, ctenophores or cnidiarians, often sufficiently large and robust to be trapped on the screen. These could emit repeated flashes or complex light displays as they were carried downwards on the mesh screen. All multipleemitting sources were counted as a single source at the depth of initial impact with the screen. Preliminary examination of data showed no major difference in proportion of different types of bioluminescent sources with depth, season or location, so analysis focussed solely on distribution of number of sources regardless of type. This does not preclude future discrimination of differences in distribution of source types.

Examination of the data shows a clear decrease in density of luminescent sources in spring from a maximum of $80 \mathrm{~m}^{-3}$ at $600 \mathrm{~m}$ depth (off-scale in the graph for 2002: Fig. 3) to a maximum of $8 \mathrm{~m}^{-3}$ at depths $>2500 \mathrm{~m}$. Between 1000 and $2000 \mathrm{~m}$ depth, in both 2001 and 2002, a layer of high abundance developed reaching maxima of 46 and $47 \mathrm{~m}^{-3}$ respectively.

An initial analysis of the source density using regression and additive modelling indicated violation of homogeneity (indicating heteroscedasticity) and therefore a $\log _{10}(y+1)$ transformation was applied. The ' +1 ' was added to avoid problems with zero observations.

As a first analysis we applied the AM to data of each individual deployment. The underlying model is given by:

$$
L F_{i}=\alpha+f\left(\text { SampleDepth }_{i}\right)+\varepsilon_{i}
$$

where $L F_{i}$ is the log-transformed luminescent flash density for observation $i$, SampleDepth ${ }_{i}$ is the corresponding sample depth, $\alpha$ is an intercept, $f$ is the smoothing function, and $\varepsilon_{i}$ is independently, normally 

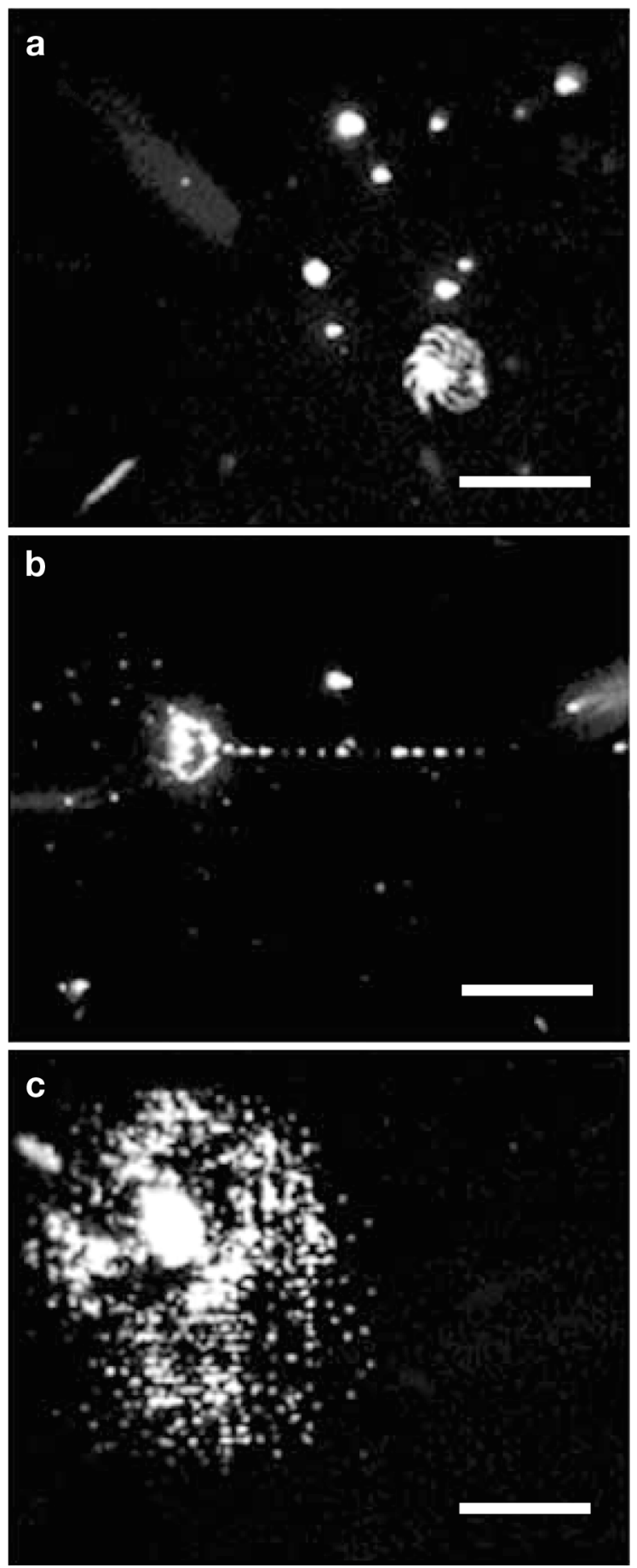

Fig. 2. Frame grabs of bioluminescent organisms impacting mesh screen $(0.5 \times 0.38 \mathrm{~m})$ during vertical profile ISIT lander deployment. (a) Spots from small planktonic organisms producing light after passing through the mesh; jelly fish (possibly Solmissus sp.), recognisable by radially symmetrical pattern of light emission, is trapped on mesh screen in focal plane of camera; 9 independent sources. (b) Unidentified siphonophore plus 2 small sources; 3 independent sources. (c) Large emission produced by unknown gelatinous organism; 1 independent source. Repetitive image structure in (b) and (c) was caused by mesh between source and camera. Scale bars $=10 \mathrm{~cm}$ distributed noise with expectation 0 and variance $\sigma^{2}$. This model is for one deployment only. All estimated smoothing curves are plotted in Fig. 4a. Profile 4 ('Deployment 4', Table 1) was excluded from this analysis owing to the limited data available, truncated by the shallow depth. These results indicated that there are 2 main underlying patterns corresponding to spring and autumn cruises. For this reason, we applied one AM model to all spring and to all autumn data. Because we were not really interested in betweendeployment differences, deployment was used as a random effect. Hence, the following additive mixed model (AMM) was fitted to data of each season:

$$
L F_{i j}=\alpha+f\left(\text { SampleDepth }_{i j}\right)+a_{j}+\varepsilon_{i j}
$$

where $L F_{i j}$ is the log-transformed luminescent flash density for observation $i$ in deployment $j$, Sample Depth $_{i j}$ is the corresponding sample depth, $\alpha$ is an intercept, $f$ is the smoothing function, $\varepsilon_{i j}$ is independently, normally distributed noise with expectation 0 and variance $\sigma^{2}$, and finally $a_{j}$ is a random component that is normally distributed with expectation 0 and variance $\sigma_{a}^{2}$. Fitted values based on the smoothing curves for both seasons obtained by the AMM are presented in Fig. 4 b.

Comparing deviances of full and nested models showed that there was no statistically significant time of day effect (spring: $p=0.37$, autumn: $p=0.13$ ), nor deployment effect (spring: $p=0.35$, autumn: $p=0.05$ ) in any season. This also indicates that differences in the geographical location of samples in the different deployments had no effect. A model validation indicated homogeneity and normality of the residuals, and the residuals did not show any non-linear pattern (Zuur et al. 2007).

The variances for the random deployment intercept and the error variance for the spring model were $\sigma_{a}^{2}=$ $0.054^{2}$ and $\sigma^{2}=0.097^{2}$. For the autumn data we had $\sigma_{a}^{2}=0.085^{2}$ and $\sigma^{2}=0.119^{2}$, indicating that there is more between-deployment variation in the autumn.

The fitted curves (Fig. 4b) show that in autumn a high abundance of bioluminescent organisms develops between 1000 and $2000 \mathrm{~m}$ depth, the peak of the abundance curve is at $1420 \mathrm{~m}$ with a value of $27.19 \mathrm{~m}^{-3}$ (25.00 and $29.43 \mathrm{~m}^{-3}$ being the lower and upper $95 \%$ confidence limits respectively). This is 3.6 times higher than the value at the corresponding depth in spring, i.e. $7.52 \mathrm{~m}^{-3}$ (5.36 to $9.66 \mathrm{~m}^{-3}$ and $95 \%$ confidence limits).

At depths $>3000 \mathrm{~m}$ there was a suggestion of increase in abundance of sources between spring (mean $=0.49 \mathrm{~m}^{-3}, \mathrm{SD}=0.30$ ) and autumn (mean $0.82 \mathrm{~m}^{-3}$, SD 0.716), with the highest values observed in October 2002 (mean $=1.17 \mathrm{~m}^{-3}, \mathrm{SD}=0.79$ ) but no valid statisti- 
cal tests could be applied since the depth range of observations differed in the different deployments.

The salinity-temperature plot (Fig. 5) from the CTD data indicates a non-homogeneous profile with density discontinuities at 850 and $2000 \mathrm{~m}$. The deep bioluminescent layer lies between these 2 depths within an intermediate layer of water identified as Mediterranean intermediate water (van Aken 2000).

\section{DISCUSSION}

The general pattern of decrease in abundance of bioluminescent sources with increasing depth during spring is similar to data from the tropical Atlantic Ocean (Priede et al. 2006), where it was found that abundance of sources decreased from $26.7 \mathrm{~m}^{-3}$ at 500 to $999 \mathrm{~m}$ depth to $0.5 \mathrm{~m}^{-3}$ at $>3500 \mathrm{~m}$, the corre-

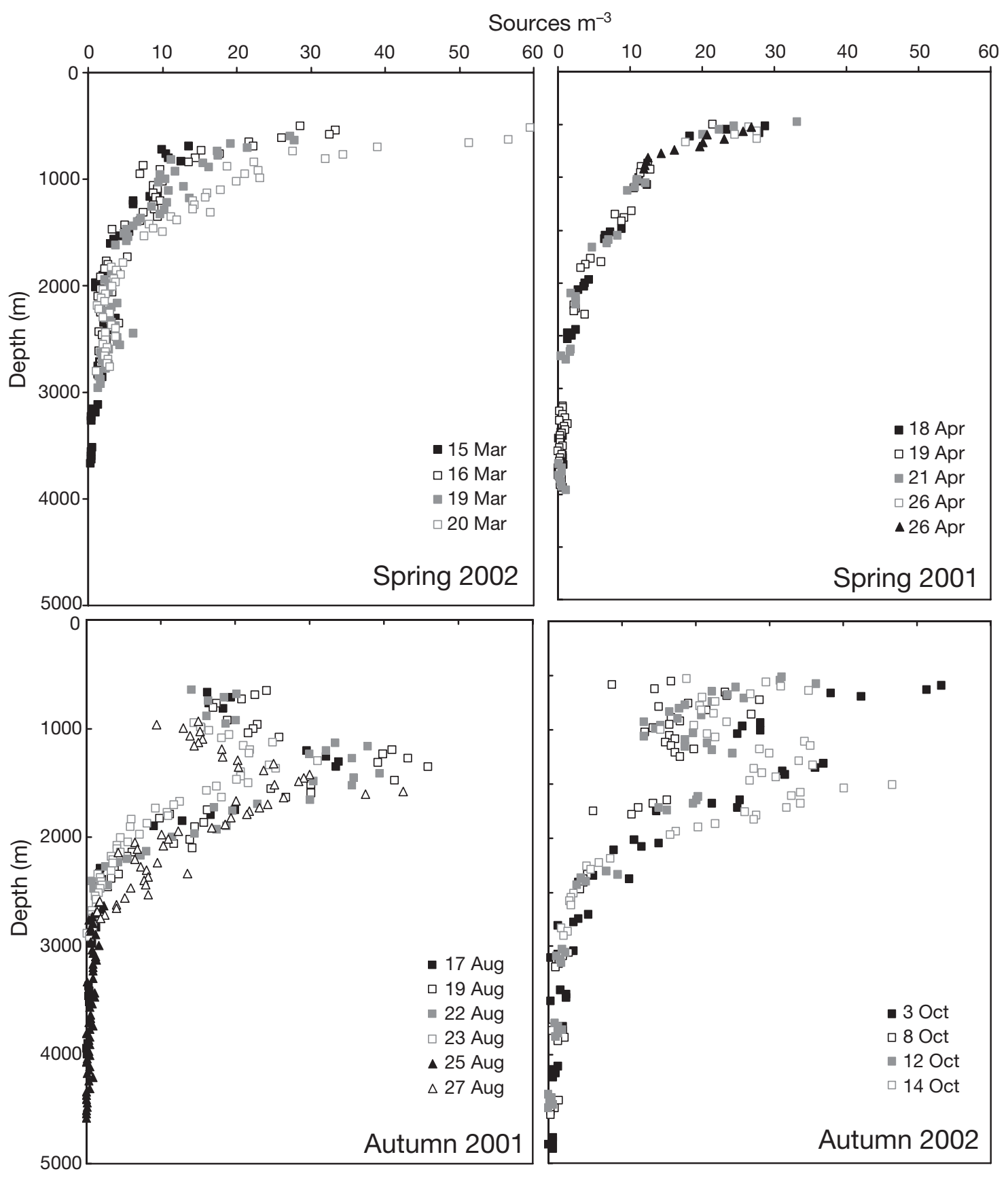

Fig. 3. Scatter plot of sources as a function depth during each of the 4 cruises. Each point is derived from a count during 1 min of descent through the water column, corresponding to a ca. $35 \mathrm{~m}$ depth interval 


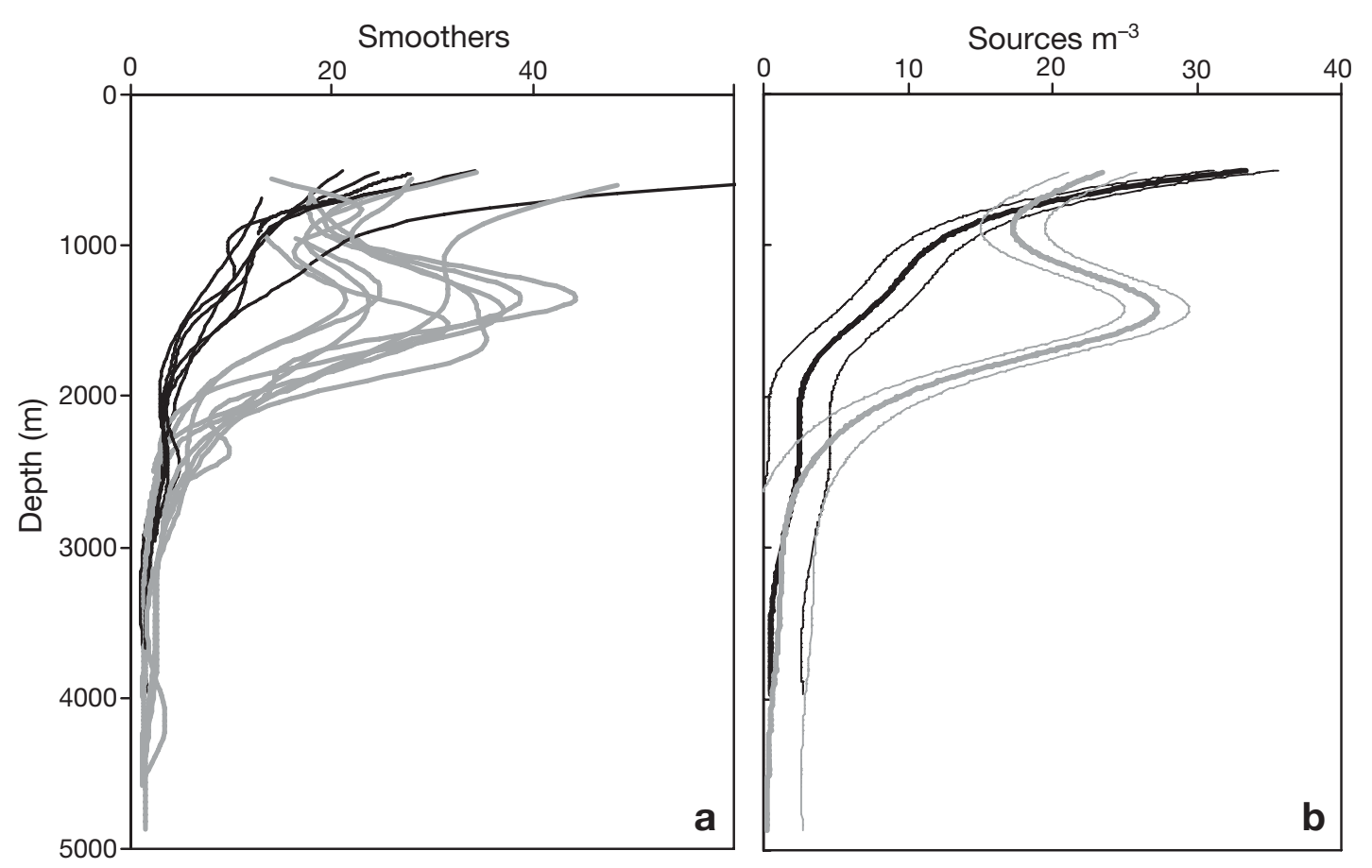

Fig. 4. (a) Fitted smoother values obtained by additive modelling for each deployment; grey lines: autumn; black lines: spring; top abscissa is in arbitrary units, normalised for each data set, and is on a log scale. (b) Fitted values of abundance of sources for spring (black lines) and autumn (grey lines) obtained by additive mixed model; parallel thinner lines are $95 \%$ confidence limits; values on the top abscissa were obtained by back-transforming smoothers from (a)

sponding values in the present study being 23.4 and $0.4 \mathrm{~m}^{-3}$. Bradner et al (1987) also reported an exponential decrease in pelagic bioluminescence in the North Pacific off Hawaii. However, the development of a deep layer of bioluminescent organisms between 1000 and $2000 \mathrm{~m}$ has not been previously reported. The phenomenon occurred $2 \mathrm{yr}$ in succession, indicating that it is probably a regular occurrence. Statistical analysis showed it is a regional scale feature with no statistically significant difference between stations spread over the Porcupine Seabight and Porcupine Abyssal Plain area of the NE Atlantic Ocean.

The deep bioluminescent layer is quite distinct from thin layers of phytoplankton aggregates, 1 to $2 \mathrm{~m}$ thick, found at pycnoclines in surface layers of the ocean (Dekshenieks et al. 2001). Widder et al. (1999) investigated aggregations of the bioluminescent copepod Metridia lucens at such thin layers between the surface and $200 \mathrm{~m}$ depth in the Gulf of Maine. Multiple layers, each $0.5 \mathrm{~m}$ thick, were observed and extended horizontally over $72 \mathrm{~m}$, corresponding to the distance travelled by their submersible during a transect. They pointed out that conventional vertical profiling systems cannot distinguish between an isolated patch and a thin layer. Our data analysis system collected data in $35 \mathrm{~m}$ depth increments so it could not discriminate layers less than ca. $100 \mathrm{~m}$ in vertical extent. The vertical and horizontal scales of the layers reported in this study are 3 orders of magnitude larger than the thin layers investigated by Widder et al. (1999).

The NE Atlantic deep bioluminescent layer described here appears to lie within a layer of Mediterranean intermediate water (MIW) characteristic of the study area with Eastern North Atlantic water (ENAW) down to approximately $750 \mathrm{~m}$ (Fig. 5) and NE Atlantic deep water (NEADW) below $2000 \mathrm{~m}$ originating from the Labrador and Norwegian Seas (Rice et al. 1991). The MIW (van Aken 2000) flows northwards from its origin at the Straits of Gibraltar and is characterised by high temperature and salinity. The presence of luminescent organisms in this layer does not reflect passive accumulation at a pycnocline, since the peak in abundance is distributed over a zone of uniform density gradient with depth (Fig. 5).

An increase in pelagic biomass within the deep bioluminescent layer may arise in 2 ways, either by advection within the northward flow of MIW or by downward export flux from overlying waters. It is unlikely that the abundant bioluminescent biomass we observe in autumn is advected from the relatively oligotrophic conditions further south or from the Mediterranean. The greatest input is likely to be from the local overlying water, this being one of the regions of the world 
with the highest seasonal surface primary production (Longhurst 1998). The annual cycle of production and subsequent transport of organic matter to the abyssal sea floor in this area has been described by Lampitt et al. (2001). Following a peak of surface primary production during March to May in each year, there is an elevated downward particle flux, detected in sediment traps, which returns to winter levels after the end of June at $1000 \mathrm{~m}$ depth and after mid- to late-September at greater depths. The peak flux at $1000 \mathrm{~m}$ depth during May to June is 100 to $250 \mathrm{mg} \mathrm{m}^{-2} \mathrm{~d}^{-1}$ compared with 1 to $50 \mathrm{mg} \mathrm{m}^{-2} \mathrm{~d}^{-1}$ dry weight in autumn and winter. We hypothesise that the bioluminescent layer below the $1000 \mathrm{~m}$ horizon represents an elevated biomass of pelagic fauna that may have actively migrated downwards or have developed in situ by feeding on material transported from above by active or passive processes. The ISIT camera has an automatic gain control which means it is not efficient at detecting steady background luminescence such as that produced by bacteria. We cannot exclude the possibility that clumps of marine snow supporting luminescent bacteria (Andrews et al. 1984) may have been responsible for some of the diffuse sources detected, but generally our data provides true estimates of the abundance of living organisms and hence an index of biomass at different levels in the water column. The study area is affected

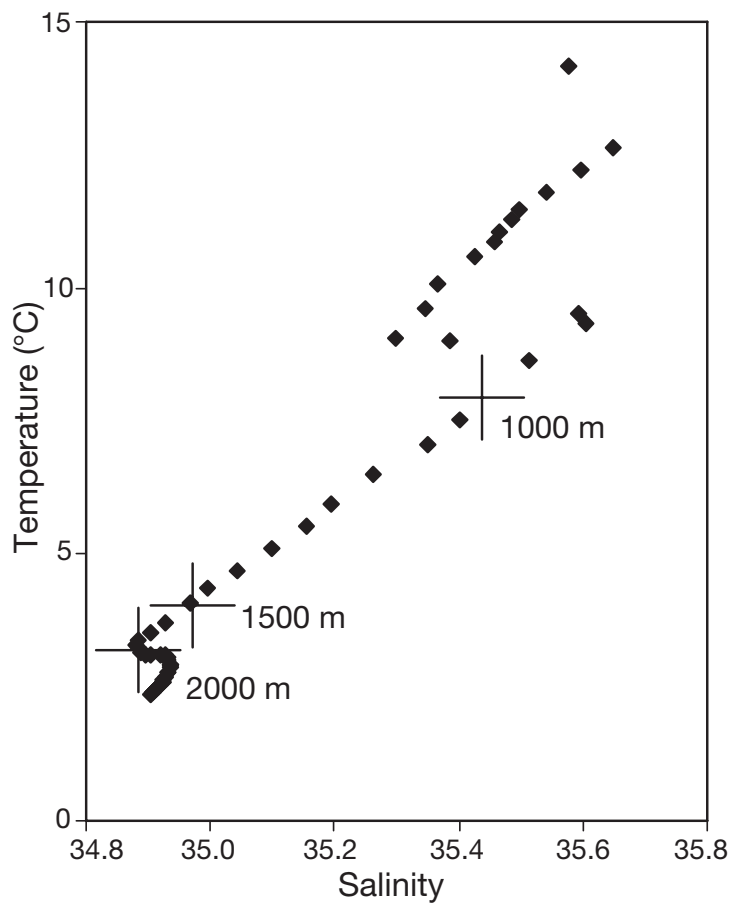

Fig. 5. Salinity and temperature data profile on 17 August 2001 in the vicinity of ISIT Lander Deployment 6 for homogenous water mass between 850 and 2000 m, corresponding to Mediterranean intermediate water. Crosses indicate depths at 1000,1500 and $2000 \mathrm{~m}$ by currents, and Lampitt et al. (2001) estimated that fast-sinking particles taking $8 \mathrm{~d}$ to reach $1000 \mathrm{~m}$ depth would have been advected $60 \mathrm{~km}$ horizontally, and used a model with a $400 \mathrm{~km}$ diameter circle at the surface as the area of origin of flux to a fixed point on the sea floor. However, they concluded that flux measurements at $1000 \mathrm{~m}$ are unreliable and suggested that this might have been the result of inefficient collection of large aggregates, blocking or effects of zooplankton swimmers on sediment traps (Lampitt et al. 2001). We suggest that processes associated with the upper boundary of the MIW and the activity of animals during the formation of the seasonal deep bioluminescent layer may help to explain some of the anomalies reported by Lampitt et al. (2001).

Whilst there is clearly sufficient seasonal downward flux of organic matter to explain the development of a deep bioluminescent layer, it is not so obvious why there should be a discontinuity with low abundance above that layer. There is no oxygen minimum zone in the study area, so the minimum in abundance of sources at $1000 \mathrm{~m}$ does not correspond to an azoic zone such as might be observed in other regions of the world (Childress \& Seibel 1998). Banse (1964) showed that the presence of oxygen minimum layers has remarkably little influence on zooplankton abundance except at oxygen concentrations below approximately $0.15 \mathrm{ml} \mathrm{l}^{-1}$, when biomass is severely decreased.

It could be suggested that by sampling during successive stages during the development of the deep bioluminescent layer we may have observed that layer migrating downwards across the $1000 \mathrm{~m}$ boundary. However, this need not necessarily be the case if there were rapid transport downwards followed by an accumulation at the 1000 to $2000 \mathrm{~m}$ horizon. During the winter we presume that some biomass was consumed, resulting in mid-water remineralisation; also, there may have been some further export downwards to the sea floor. There was weak evidence of an increase in abundance below $3000 \mathrm{~m}$ in October, indicating that some of the export to the abyss may have been due to active migration. The following spring there was no evidence of the deep luminescent layer.

Many regions of the world's oceans are characterised by a seasonal peak of surface primary productivity (Longhurst 1998). We hypothesise that in all such areas there is potential for seasonal formation of a deep bioluminescent layer. Further studies are required to determine whether formation of a distinct deep bioluminescent layer is dependent on the presence of an intermediate water mass or can occur in more homogeneous environments.

In a study of benthic bioluminescence in the Porcupine seabight, Gillibrand et al. (2006) found maximum bioluminescent activity at $1000 \mathrm{~m}$ depth. Since this 
coincides with the autumn minimum in pelagic luminescence in the present study, it seems that the benthic and pelagic luminescent faunas are distinct and a model of pelagic biomass impinging on the slope cannot account for the benthic bioluminescent hotspots at 1000 m observed by Gillibrand et al. (2006).

Acknowledgements. E.J.V.G. was supported by a NERC studentship and cruises were funded by NERC grant GR3/12789 to I.G.P. We thank the ship's company of RRS 'Discovery' for enabling this work and the help and advice of Professor Peter Herring (Southampton) and Dr. Julian Partridge (Bristol).

\section{LITERATURE CITED}

Andrews CC, Karl DM, Small LF, Fowler SW (1984) Metabolic activity and bioluminescence of oceanic faecal pellets and sediment trap particles. Nature 307:539-541

Banse K (1964) On the vertical distribution of zooplankton in the sea. Prog Oceanogr 2:53-125

Battle EJV, Priede IG, Collins MA, Bagley PM (2002) Seasonal variation in bioluminescence in the Porcupine Seabight, NE Atlantic Ocean to $4800 \mathrm{~m}$ depth. In: Stanley PE, Kricka LJ (eds) Bioluminescence and chemiluminescence, progress and current applications. World Scientific, River Edge, NJ, p 379-382

Bradner H, Bartlett M, Blackinton G, Clem J (1987) Bioluminescence profile in the deep Pacific Ocean. Deep-Sea Res I 34:1831-1840

Childress JJ, Seibel BA (1998) Life at stable low oxygen levels: adaptations of animals to oceanic oxygen minimum layers. J Exp Biol 201:1223-1232

Clarke GL, Hubbard CJ (1959) Quantitative records of luminescent flashing of oceanic animals at great depths. Limnol Oceanogr 4:163-180

Clarke GL, Kelly MG (1965) Measurements of diurnal changes in bioluminescence from the sea surface to 2000 meters using a new photometric device. Limnol Oceanogr 10:R54-R66

Dekshenieks MM, Donaghay PL, Sullivan JM, Rines JEB, Osborn TR, Twardowski MS (2001) Temporal and spatial occurrence of thin phytoplankton layers in relation to physical processes. Mar Ecol Prog Ser 223:61-71

Faraway JJ (2006) Linear models with R. Chapman \& Hall, London

Editorial responsibility: Howard Browman (Associate Editorin-Chief), Storebø, Norway
Gillibrand EJV, Bagley P, Jamieson A, Herring PJ, Partridge JC, Collins MA, Milne R, Priede IG (2007) Deep sea benthic bioluminescence at artificial food falls, 1000 to $4800 \mathrm{~m}$ depth, in the Porcupine Seabight and Abyssal Plain, North East Atlantic Ocean. Mar Biol 150:1053-1060, doi: $10.1007 / \mathrm{s} 00227-006-0407-0$

Hastie T, Tibshirani RJ (1990) Generalized additive models. Chapman \& Hall, London

Herren CM, Haddock SHD, Johnson C, Moline MA, Orrico CM, Case JF (2005) A multi-platform bathyphotometer for fine-scale, coastal bioluminescence research. Limnol Oceanogr Methods 3:247-262

Herring PJ (ed) (1990) Light and life in the sea. Cambridge University Press, Cambridge

Lampitt RS, Bett BJ, Kiriakoulakis K, Popova EE, Ragueneau O, Vangriesheim A, Wolff GA (2001) Material supply to the abyssal seafloor in the Northeast Atlantic. Prog Oceanogr 50:27-63

Longhurst AR (1998) Ecological geography of the sea. Academic Press, San Diego, CA

Miller SD, Haddock SHD, Elvidge CD, Lee TF (2005) Detection of a bioluminescent milky sea from space. Proc Natl Acad Sci USA 102:14181-14184

Priede IG, Bagley PM, Way S, Herring PJ, Partridge JC (2006) Bioluminescence in the deep sea: free-fall lander observations in the Atlantic Ocean off Cape Verde. Deep-Sea Res I 53:1272-1283

Rice AL, Billet DSM, Thurston MH, Lampitt RS (1991) The Institute of Oceanographic Sciences Biology programme in the Porcupine Seabight: background and general introduction. J Mar Biol Assoc UK 71:281-310

van Aken HM (2000) The hydrography of the mid-latitude Northeast Atlantic Ocean: II. The intermediate water masses. Deep-Sea Res I 47:789-824

Webster MS, Roos CE, Roberts A, Okada A and 11 others (1991) Mechanical stimulation of bioluminescence in the deep Pacific Ocean. Deep-Sea Res 38:201-217

Widder EA, Johnsen S (2000) 3D spatial point patterns of bioluminescent plankton: a map of the 'minefield'. J Plankton Res 22:409-420

Widder EA, Johnsen S, Bernstein SA, Case JF, Neilson DJ (1999) Thin layers of bioluminescent copepods found at density discontinuities in the water column. Mar Biol 134: 429-437

Wood SN (2006) Generalized additive models. An introduction with R. Chapman \& Hall, London

Zuur AF, Ieno EN, Smith GM (2007) Analysing ecological data. Springer-Verlag, Berlin

Submitted: August 25, 2006; Accepted: November 19, 2006

Proofs received from author(s): June 18, 2007 